\title{
INTEGRITY, SUSTAINABILITY, AND INTELLECTUAL CAPITAL CHALLENGES IN MANAGEMENT EDUCATION IN THE ERA OF ARTIFICIAL INTELLIGENCE
}

\section{Peter Odrakiewicz}

Gniezno College Milenium, Gniezno, and Global Partnership Management Institute, Poznan, Poland https://orcid.org/0000-0001-8321-3041

\section{Mykola Orlykovskyi}

Gniezno College Milenium, Gniezno, Poland https://orcid.org/0000-0001-9296-623X

\section{Michael Gaylord}

Global Partnership Management Institute, Poznan, Poland

OMESTE

JEL Category: A13, M14

\begin{abstract}
This paper seeks to discuss challenges for management education and integrity capital promulgation in innovative ways in the era of Artificial Intelligence (Al) in education and business practice. The authors present some examples of innovative strategies in the new educational era characterized by globalized Al. How will the Al co-instruction affect the acquisition of intellectual capital? Building on previously published articles and ongoing new research, and maintaining that lack of sustainable management practices, corruption in management leads to social exclusion. The paper presents innovative methods of organization's ethics and integrity branding management in diverse organizations focusing on intellectual capital management and sustainability. It proposes that the facilitation of social inclusion can be considered an innovative approach in both business management and management education. It is an opening and invitation to further exploration for finding better means for management education, integrity competencies and intellectual capital, teaching, sharing in business and society in the era of $A$ I in educational institutions and business organizations. In addition, it seeks to build corruptionpreventative contexts to construct corruption-free organizations that benefit their owners, shareholders, and community stakeholders. A particular focus is on higher educational institutions in this research.
\end{abstract}

Address of the corresponding author:

Keywords: management, Al, integrity, Peter Odrakiewicz sustainability, capital, integrity, intellectual capital 


\section{INTRODUCTION}

Artificial intelligence is becoming an increasing part of our daily lives. We can expect that by 2024, up to $47 \%$ of learning management tools will have artificial intelligence capabilities (Schmelzer, 2019). Hence, it is not surprising that educational institutions are trying to develop more talent to facilitate the spread of this intelligence across many learning environments. Recognizing that artificial intelligence is transforming the education industry, Schmelzer points out that Al systems are being used to tailor and personalize learning for each student. Instead of creating a unique curriculum for all students, with augmented intelligence assistance teachers will be able to meet the individual needs of students using different materials from a wide range of materials planned for the same core curriculum. The authors of this paper note that, due to the high degree of personalization of $\mathrm{Al}$ methods in the classroom, the learning profiles of each student can be acutely tailored to meet his or her unique experiences, abilities, and ways of learning.

Now the authors ask: How does integrity fit into this new Al-augmented reality? In our previous research, we examined how integrity, and specifically, integrity in an organizational context, can be defined. There is still no simple explanation for this question. Organizations may understand it differently. Integrity has been defined as the quality of having strong and consistent moral principles that one refuses to change (Cambridge, 2019). Marriam-Webster (2019) describes it as "firm adherence to a code of especially moral or artistic values (incorruptibility)" and "an unimpaired condition (soundness).". Most definitions agree that integrity fundamentally involves the ability to act not in one's interest, but the interest of others. Thus, the authors would like to note that, because implementing augmented intelligence systems is a venture that involves striving to better meet students' individual needs, it would appear that integrity plays a dynamic and significant role in this process.

\section{LITERATURE AND SUBJECT REVIEW}

Reputable business institutions have singled out integrity as a fundamental, necessary, and teachable principle in business practice. Columbia University, for instance, has a committee on corporate governance and ethics which is designed to help business students make ethically minded decisions. According to Ray Horton (Forbes, 2002), it is possible to provide students with the skills to deal with difficult situations by giving them practical clues about decision-making when there is a conflict between company demands and their code of behavior. We can see how this is vital, as integrity involves accepting and choosing to live by one's principles and regularly showing good character by avoiding corruption (McCombs, 2017). If we explain it with plain managerial words, we can define integrity as the formal relation to oneself. In an organizational context, we should examine the integrity principle of consistency. Is it possible to evaluate the manager's behavior in the organizational context based on a body of his or her integrity standards? Further exploring integrity could provide us with some answers.

In this case, the authors seek to explore how this hyper-personalized digital content may revolutionize learning in management in the areas of integrity, anti-corruption, and social innovation management. We concur with Schmelzer that providers of mainstream textbooks now have their information broken down or condensed into smaller study guides, chapter summaries, flashcards, as well as short, smart, notes for better reading and understanding. Learning, therefore, less often uses print, and soon there will be little or no use of hard copy textbooks for learning (Schmelzer, 2019). This concept seems to suggest the elimination of printed textbooks, which is perhaps an exaggeration. Nevertheless, Al in management education, and across higher education in general, presents a paperless online interactive interface that assists communication between learners and faculty for communicative purposes. However, it remains unclear how issues as complex as intellectual capital in integrity, anticorruption, and social innovation in management can be taught and transferred more effectively and efficiently using this level of artificial intelligence, and at this point. 
3 THE RELEVANCE OF INTEGRITY ISSUES IN HIGHER EDUCATION

Integrity issues in organizations are closely related to the notion of ethics. The practical goal of integrity issues is to solve the problem of how to make the best decision in an ethically difficult business context. The main known tools for the application of the principles of business ethics are principles and codes of ethics. However, the implementation of various concepts and ethics programs is neither sufficient to equip students and workers with integrity in management and related ethical competencies nor will it ensure that they maintain integrity in an organizational context, for example, Corporate Social Responsibility using artificial intelligence learning and the training environment.

Integrity issues are becoming increasingly important due to the benefits of international business and efficiency in searching for new customers, cooperating with firms, and finding partners. In an organizational context, they are going to become increasingly important. That is the case primarily with the crisis facing organizations operating during financial crises when confidence in many companies is reduced.

Poor integrity management, a lack of consultation with employees and owners or their representatives, and company leaders who knowingly or unknowingly perpetuate a toxic management environment aimed to increase profits regardless of negative consequences can reduce integrity skills acquisition in organizational contexts. Lack of integrity competence transfer in organizations can result in people delaying or refusing applicating of this philosophy in the managerial process. The personal attitudes of individual employees, which may be due to lack of motivation or dissatisfaction at work, can lead to corrupt practices in situations of insufficient or inappropriate integrity and anticorruption training in organizational contexts. That is because integrity, as noted above, suggests a person whose self is sound, undivided, and ethical.

There is no shortage of academics who advocate that new teaching tools, added to post-secondary institutions promptly, should combat corrupt practices and lack of integrity. According to Stachowicz-Stanusch and Wankel (2011, p. 119), examples of "corporate, national and international ethical and financial scandals and crises have created a need to bolster the ethical acumen of managers through business education imperatives." Their book, Management Education for Integrity, explains how curricula should be rejuvenated to ensure an elevated level of integrity in management education. They suggest, among other things, measuring best practices in management education for integrity capacity, critiquing ethics education in management, encouraging moral engagement via ethics courses, and using a scenario-based approach as a teaching tool to promote integrity awareness.

\section{PROBLEM FORMULATION - HOW Al IS BEING USED IN MANAGEMENT EDUCATION TODAY}

According to Schmelzer (2019), in addition to customized materials, artificial intelligence systems are being used to supplement tutoring with personal, conversational education assistants. These autonomous conversational agents can answer questions from students, help with learning or assignments, and reinforce concepts with additional materials that can help teach the curriculum. These intelligent assistants are also adaptive. Each of the students can learn at their own pace or within their specific time frames.

Educators in some universities increasingly use voice assistants in the classroom environment as Google Home, Microsoft Cortana, and others, giving students a chance to interact with educational material, for instance, in their homes and while commuting, without the interaction with the teachers. However, it remains hard to envision how such complex issues as anti-corruption, integrity in management, and similar paradigms and areas one can better learn via widespread use of these voice assistants at this stage of their development. Although artificial intelligence use in the classroom is a potentially key area for consideration and development, it should be considered only an additional tool in educating present and future students, future employees, innovators, and leaders about the importance of integrity and anti-corruption issues in business, and professional life. All means must be used.

The digital, dynamic nature of artificial intelligence 
offers many opportunities for student engagement, claims Faggella (2019). They cannot be found in outdated textbooks or the fixed environment of the typical four-walled classroom. But together, $\mathrm{Al}$ and dynamic classroom engagement have the potential to accelerate the discovery of new learning frontiers and encourage the creation of innovative technologies. Some of this observation is explored further at Faggella's company Emerj. (Faggela, 2019) Here, participants examine how tomorrow's businesses and government leaders are educated on artificial intelligence practices. The company anticipates how these aspirants will play roles in the future development of this intelligence. The following are some examples of ways in which it is being pioneered and applied in education:

- Smart Content - A technology that attempts to condense textbooks into a tool for exam preparation.

E. g. as true or false questions.

- Intelligent Tutoring Systems - Personalized electronic tutoring customized to the learning styles and preferences of the student.

- Virtual Facilitators and Learning Environments - Virtual human guides and facilitators for use in different educational and therapeutic environments.

"While the applications included are in use in some form today, one could argue, that most are still at an unadvanced stage in terms of envisioned longterm objectives", maintains Faggella (2019). The authors of this chapter concur with Faggella that many artificial intelligence systems used in postsecondary education today are still quite raw. From those listed above, Intelligent Tutoring Systems, according to Faggella, seem to have made the most progress over the last 20 years-it was one of the original concepts for applications of artificial intelligence in higher education. Nevertheless, all the listed methods potentially can help shape a coming generation of more personalized learning and responsive teaching.

An ITS (Intelligent Tutoring System), according to Dašić et al. (2016), is a complex, integrated software system that applies the principles and methods of artificial intelligence to the problems and needs of teaching and learning. It considers a student's level of knowledge and learning strategies used to increase or correct the student's knowledge. These techniques are intended to support and improve the learning process in a selected area of knowledge while respecting the individuality of the learner. E-learning is a crosssection of two worlds: the world of information and communication technology on the one hand, and the world of education on the other; it is especially valuable when used as part of a well-planned and organized environmental education. However, secure e-learning is not a 'magic sphere' that will replace existing educational theories, principles, and norms. Instead, it is a new paradigm of learning that utilizes the assistance of different devices based on electronic technology; with the help of an ITS, therefore, it better supports individualized teaching and learning. These tutoring systems have helped improve the teaching process, through adapting it to the students' individual needs and thus have proven in education. Many successes have been achieved by recognizing this uniqueness amongst learning styles and by using the vast array of different teacher-student interactions, especially in some traditional teaching strategies improvement (among them: partnership, mentoring, development of collaborative software, and learning through work).

\section{INITIAL DISCUSSION}

However, the authors invite further examination of the emerging autonomous conversational agents, to discover whether these agents are successfully addressing complex integrity issues from students undergoing training in this area. Further, are they assistance with learning and assignment tasks that consider how to deal with ethical dilemmas, and use additional materials that can help reinforce the curriculum concerning integrity and anti-corruption? At the management level, these issues are quite complex and thus the customized artificial intelligence materials being promoted would need to be well-designed. It appears that further research, and more in-depth consideration, is needed if ethical elements that prevent corruption must be fully incorporated into autonomous conversation agents.

Organizations that promote integrity, values, and ethics have many advantages vis-à-vis other organizations (Dogra, 2010). First, employees that emphasize ethical conduct experience less integrity-related stress, as they are less inclined to 
compromise their values. Secondly. In such organizations, misconduct is more often immediately reported to individual managers responsible for resolving ethical misconduct issues. Thirdly. Instances of misconduct are minimized and employee satisfaction in such ethics-focused organizations is higher than in organizations without a similar emphasis. Ethical issues in the workplace can be resolved if proper procedures are in place. Upholding ethics promotes a better working environment, and at the same time, creates a good reputation for the business. Both contribute to higher work productivity and profits.

E-learning as a Possible Solution for Intellectual Capital Transfer while Aiding Integrity Capital Promulgation

When technologies are developing very quickly, to be competitive, training systems improvement should be prioritized, including knowledge acquisition utilizing modern $\mathrm{Al}$ achievements in education. One method for supporting these training systems is e-learning and Al-supported learning, which are viable additions, not alternatives, to traditional education. They offer high levels of knowledge, are universally available, and are inclusive in allowing a wide range of people who seek to learn, including those suffering from unemployment or disability, to access knowledge.

Many colleges and universities also provide blended learning, offered in synchronic and asynchronous mode. The success of this method of education in international management education will depend on the availability of financial resources and the willingness of the present faculty to endorse this innovation in teaching. Great attention must be always paid to integrity capital promulgation issues.

The role of managers is to incorporate integrity and anticorruption training programs in organizational contexts into the modern communications arena using social media. E. g., Linkedln, Facebook, and Twitter, real-life case studies, work-study-internship examples, and blogs on integrity-related discussions, and incorporating artificial intelligence as a tool supporting learning and knowledge acquisition in the above areas.

\section{HUMANISM IN BUSINESS}

In examining the implications of humanism in the business world, Peter Ulrich (2009) questions the purpose of our economic system and ponders the consequences of an economy the focuses more on enhancing the quality of life. Much has been written about business and society, yet not a lot of academic writing has questioned the primacy of GDP growth, profit maximization, and individual utility maximization. Even developments with a humanistic touch, such as stakeholder participation, corporate social responsibility, or corporate philanthropy serve the same goal: to foster long-term growth and profitability.

Humanism in Business (Spitzeck, Pirson, Amann, Khan, \& Kimakowitz, 2009) questions these assumptions and investigates the possibility of creating a human-centered, value-oriented society based on humanistic principles. In the paper, an international team of academics and practitioners present philosophical, economic, psychological, and organizational arguments that show how humanism can be used to understand and transform businesses at systems, on organizational and individual levels. This information is of interest to academics, practitioners, and policymakers concerned with business ethics and the relationship between business and society. The functions of various organizational elements can dictate moral and ethical concerns. Therefore, diverse and inherently moral and ethical issues are embedded in the power structure of most organizations. When power is unequally distributed among organizational members or groups, the emergence of moral and ethical conflicts is virtually inevitable. These are just a few examples of how the complexity of the organizational context can further complicate moral and ethical matters. The inherent limitations of mandatory integrity and ethics codes in such contexts seem clear. Organizations with genuine commitments to moral aims must actively pursue broader, more innovative approaches to building integrity and morality among the various dimensions of organizational structure and functioning. Artificial intelligence will certainly be a significant and growing part of education and management; however, the issues of integrity, sustainability, and ethics must be embedded in its programming. Otherwise, we risk dehumanization in workplaces that are already fractured in many ways. 


\section{CONCLUSION}

Mandatory integrity capital promulgation programs are necessary for all educational and training environments and should always be a significant part of an organization's framework. Clear guidelines established on formal ways create a baseline for expectations critical to the general well-being of the organization. Clear communication of certain principles and procedures are essential in many functional areas to meet externally- and internally- imposed standards. Adherence to such standards is often so significant that reporting and enforcement programs are critical components of operations aiding in lessening social exclusion challenges and promoting integrity as social innovation.

However, the thoroughly moral organization must go far from principle-driven mandatory ethics and integrity capital promulgation in education and management programs. There are a variety of concept systems that one might use to discuss the nature of moral functioning at the organization's level. Leadership topics often include ethical dimensions. The role of values and norms in organizational culture is closely related to integrity and morality. The authors think they need to be studied using innovative case studies and synchronous delivery methods approach such as role-playing, video interviews, integrity capital promulgation project-participation, and intensive social media use in management education. That, it is considered, will educate students on socially responsible actions and on those which prevent social exclusion, and it will facilitate active management and education in spheres that support social inclusion.

More study is needed on integrity capital promulgation training and integrity capital competencies in organizations. Also, greater support is needed in using social media or similar synchronous and similar learning methods in integrity and anti-corruption, and socially inclusive knowledge acquisition. In the view of these authors, that can be achieved using real-life examples from organizations, making the organization much more likely to gain integrity capital competencies and anti-corruption intellectual capital. Professional integrity capital management in education, and the workplace, is the key to creating a balanced and socially responsible environment and society.

More research is needed on the question: Will artificial intelligence support humans in their managerial and educational roles or down the human element in education and management?

\section{WORKS CITED}

Cambridge. (2019, 10 12). integrity. Retrieved from Cambridge online dictionary: https://dictionary.cambridge.org/dictionary/english/integrity

Dašić, P., Dašić, J., Crvenković, B., \& Šerifi, V. (2016). A review of intelligent tutoring systems in elearning. Annals of the Oradea University - Fascicle of Management and Technological Engineering, 85-90.

Dogra, M. (2010). Ethnicity and Culture and Their Relationship to Health Care. Research Evaluation. doi:10.1093/innovait/inp158

Faggela, D. (2019, 11 21). Examples of Artificial Intelligence in Education. Retrieved from EMERJ: https://emerj.com/ai-sector-overviews/examples-of-artificial-intelligence-in-education/

Forbes. (2002, 10 4). Can Integrity be Taught? Retrieved from Forbes: https://www.forbes.com/2002/10/04/1004virtue.html?sh=663b82d65ee7

McCombs. (2017). Integrity [Video]. Retrieved from Ethics Unwrapped: https://ethicsunwrapped.utexas.edu/glossary/integrity

Merriam-Webster. (2019, 10 5). Integrity. Retrieved from Online dictionary: https://www.merriamwebster.com/dictionary/integrity

Schmelzer, R. (2019, 07 12). Al Applications in Education. Retrieved from Forbes: https://www.forbes.com/sites/cognitiveworld/2019/07/12/ai-applications-ineducation/\#1cf9294462a3

Spitzeck, H., Pirson, M., Amann, W., Khan, S., \& Kimakowitz, E. v. (2009). Humanism in Business. Cambridge: Cambridge University Press. 
Stachowicz-Stanusch, A., \& Wankel, C. (2011). Management education for integrity, ethically educating tomorrow's business leaders (1st ed.). Emerald Group.

Ulrich, P. (2009). Towards a civilized market economy: economic citizenship rights and responsibilities in service of a humane society. In H. Spitzeck, M. Pirson, W. Amann, \& S. Khan (Eds.), Humanism in Business (pp. 143-155). Cambridge University Press.

Received for publication:

Revision received:

Accepted for publication:
21.12.2021

25.12.2021

06.01 .2022

\section{How to cite this article?}

Style - APA Sixth Edition:

Odrakiewicz, P., Orlykovskyi, M., \& Gaylord, M. (2022, 01 15). Integrity, sustainability, and intellectual capital challenges in management education in the era of artificial intelligence. (Z. Cekerevac, Ed.) MEST Journal, 10(1), 36-42. doi:10.12709/mest.10.10.01.04

Style - Chicago Sixteenth Edition:

Odrakiewicz, Peter, Mykola Orlykovskyi, and Michael Gaylord. 2022. "Integrity, sustainability, and intellectual capital challenges in management education in the era of artificial intelligence." Edited by Zoran Cekerevac. MEST Journal (MESTE) 10 (1): 36-42. doi:10.12709/mest.10.10.01.04

Style - GOST Name Sort:

Odrakiewicz Peter, Orlykovskyi Mykola and Gaylord Michael Integrity, sustainability, and intellectual capital challenges in management education in the era of artificial intelligence [Journal] // MEST Journal / ed. Cekerevac Zoran. - Belgrade - Toronto : MESTE, 01 15, 2022. - 1 : Vol. 10. - pp. 36-42.

Style - Harvard Anglia:

Odrakiewicz, P., Orlykovskyi, M. \& Gaylord, M., 2022. Integrity, sustainability, and intellectual capital challenges in management education in the era of artificial intelligence. MEST Journal, 15 01, 10(1), pp. 36-42.

Style - ISO 690 Numerical Reference:

Integrity, sustainability, and intellectual capital challenges in management education in the era of artificial intelligence. Odrakiewicz, Peter, Orlykovskyi, Mykola and Gaylord, Michael. [ed.] Zoran Cekerevac. 1, Belgrade - Toronto : MESTE, 01 15, 2022, MEST Journal, Vol. 10, pp. 36-42 